\title{
Acute and chronic effects of aerobic exercise on blood pressure in resistant hypertension: study protocol for a randomized controlled trial
}

\author{
LS Nascimento ${ }^{1,2}$, AC Santos ${ }^{1,2}$, JMS Lucena ${ }^{3}$, LGO Silva $^{1}$, AEM Almeida ${ }^{1}$ and MS Brasileiro-Santos ${ }^{1,2^{*}}$
}

\begin{abstract}
Background: Resistant hypertension is a specific condition that affects approximately $10 \%$ of subjects with hypertension, and is characterized by persistently high blood pressure levels even using therapy of three or more antihypertensive agents or with blood pressure control using therapy with four or more antihypertensive agents. Changes in lifestyle, such as physical exercise, are indicated for controlling blood pressure. However, investigating studies about this therapy in individuals with resistant hypertension are few.
\end{abstract}

Methods/design: This is a randomized controlled clinical trial. Forty-eight patients with resistant hypertension will be submitted to perform four short-term interventions: aerobic exercise sessions (mild-, moderate- and high-intensity) and control session, in random order and on separate days. After the short-term sessions, the patients will be randomly allocated into four groups for 8 weeks of follow-up: mild-, moderate- and high-intensity aerobic exercise, and a control group. The primary outcome is the occurrence of blood pressure reduction (office and ambulatory analysis, and acute and chronic effects). Secondary outcomes are autonomic and hemodynamic mechanisms: cardiac and vasomotor autonomic modulation, spontaneous baroreflex sensitivity, forearm blood flow and vascular resistance.

Discussion: The importance of exercise for hypertension has been known for decades, but little is known about the effects on patients with resistant hypertension. This study will help to understand whether different aerobic exercise intensities can induce different responses, as well as by what mechanisms adjustments in blood pressure levels may occur.

Trial registration: ClinicalTrials.gov, ID: NCT02670681. Registered on 28 January 2016 (first version); Brazilian Registry Platform Clinical Trials: protocol RBR-5q24zh. Registered on 24 June 2015.

Keywords: Hypertension, Exercise, Post-exercise hypotension, Autonomic nervous system, Hemodynamics

\section{Background}

Systemic hypertension is a multifactorial clinical condition characterized by persistently high blood pressure (BP) levels with systolic BP (SBP) $\geq 140 \mathrm{mmHg}$ and/or diastolic BP (DBP) $\geq 90 \mathrm{mmHg}$ [1]. In a particular condition, hypertension can be classified as resistant

\footnotetext{
* Correspondence: sbrasileiro@pq.cnpq.br

${ }^{1}$ Laboratório de Estudos do Treinamento Físico Aplicado a Saúde, Departamento de Educação Física, Universidade Federal da Paraíba, Castelo Branco I, CEP 58051-900 João Pessoa, Paraíba, Brasil

${ }^{2}$ Programa Associado de Pós-Graduação em Educação Física UPE/UFPB, João Pessoa, Paraíba, Brasil

Full list of author information is available at the end of the article
}

hypertension, which is characterized by persistently high BP levels even with therapy involving three or more antihypertensive agents in appropriate doses and combinations, or controlled BP in therapy with four or more antihypertensive agents [2], as well as failure to maintain BP levels below 140/90 $\mathrm{mmHg}$, even with the appropriate use of three or more antihypertensive agents and at least one diuretic being necessary [3]. The prevalence of resistant hypertension is highly variable depending on the evaluated population, but approximately $10 \%$ of the hypertensive population has this resistance [1].
C Biomed Central

(c) The Author(s). 2017 Open Access This article is distributed under the terms of the Creative Commons Attribution 4.0 International License (http://creativecommons.org/licenses/by/4.0/), which permits unrestricted use, distribution, and reproduction in any medium, provided you give appropriate credit to the original author(s) and the source, provide a link to the Creative Commons license, and indicate if changes were made. The Creative Commons Public Domain Dedication waiver (http://creativecommons.org/publicdomain/zero/1.0/) applies to the data made available in this article, unless otherwise stated. 
Given the lack of pharmacological responsiveness of this population, nonpharmacological strategies are encouraged. These include restricting salt intake, reducing alcohol consumption, stopping smoking, losing weight, changing diet and doing regular physical activity [1]. The importance of physical exercise in promoting a reduction in resting BP levels is well established in the academic literature, and is a phenomenon known as post-exercise hypotension (PEH) [4]. PEH could occur due to alterations in diverse mechanisms such as reduced peripheral vascular resistance and/ or cardiac output [5-7], increased vasodilator bioavailability $[6,8,9]$, reduced sympathetic nerve activity, increased parasympathetic modulation and improved baroreflex sensitivity $[10,11]$.

Previous studies have found decreased BP levels after a single aerobic exercise session for hypertensive patients [12-21]. There is a wide range of magnitude (between $-2 \mathrm{mmHg}$ and $-12 \mathrm{mmHg}$ ) and duration (between 4 and $16 \mathrm{~h}$ ) of $\mathrm{PEH}$, which is probably due to individual characteristics and different aerobic exercise protocols (e.g., intensity and duration) [22]. BP reduction is also found in follow-up studies [23-27]. In a meta-analysis of normotensive and hypertensive patients, Fagard [28] showed a $3.3-\mathrm{mmHg}$ decrease in SBP, and $3.5 \mathrm{mmHg}$ for DBP. Such reductions in chronic levels are often more discreet, but very important clinically, where a $2-\mathrm{mmHg}$ reduction may decrease the risk of myocardial infarction by about $6 \%$, and the risk of developing coronary artery disease by $4 \%$ [3].

For subjects with resistant hypertension, there are few studies involving physical exercise. Clinical trials [29-32] have identified significant reductions in SBP and DBP levels after 12 weeks of continuous moderate aerobic exercise training (based on lactate concentration) and strength training (resistance exercise in a pool). Recently, a crossover trial investigated short-term exercise (mild and moderate intensity) effects in resistant hypertension and found significant reductions in both SBP and DBP levels at both intensities [33]. These studies show the importance of physical exercise as a therapeutic strategy for this population. However, it is still unclear which physical exercise characteristics can result in better outcomes in follow-up studies for patients with resistant hypertension, as well as the possible mechanisms linked to adjustments in BP levels. Exercise characteristics, such as intensity, duration, frequency and type, are associated with different BP responses. Aerobic exercise intensity is a characteristic that seems to influence the magnitude and duration of $\mathrm{PEH}$, but there is no consensus about the magnitude of hypotension and/or the intensity which is more effective in reducing BP levels. Eicher et al. [34] reported that high-intensity interval-training exercise promotes $\mathrm{PEH}$; however, other authors found that lower intensities have been more effective in reducing BP levels [35]. Therefore, studies are inconclusive in presenting the most effective intensity or identifying differences in hypotensive responses to varying intensities used in clinical trials $[17,25$, 36-39].

Thus, a trial testing the efficacy of different intensities of aerobic exercise to control BP is necessary and important. Considering the recent findings on physical exercise in resistant hypertension and different responses to exercise intensities, it is hypothesized that short-term sessions of aerobic exercise of mild, moderate and high intensities can promote PEH as a primary outcome; furthermore, follow-up aerobic exercise training for 8 weeks can reduce the BP levels. Additionally, adjustments are expected in the autonomic and hemodynamic variables, such as reduced sympathetic modulation, increased parasympathetic modulation, improved baroreflex sensitivity, decreased forearm vascular resistance, and a consequent increase in blood flow.

\section{Rationale}

It is known that hemodynamic, humoral and neural changes are associated with hypertension. Pharmacological therapy affects these variables and helps to control BP. However, some subjects with hypertension are nonrespondent to this therapy, and are classified as resistant hypertensive patients. Acute and chronic aerobic exercise reduces BP, thereby adjusting autonomic and hemodynamics, improving parasympathetic modulation, baroreflex sensitivity, vasodilator response and attenuates sympathetic modulation and vascular resistance. Different aerobic exercise intensities could stimulate diverse physiological mechanism responses, and, therefore should produce different adjustments in BP. Even when not responding properly to drug strategies that act on different variables depending on antihypertensive class, it is possible that simultaneous autonomic and hemodynamic adjustments caused by physical exercise promote reduced BP.

\section{Research question}

Is there reduced BP after different short-term aerobic exercise intensities in resistant hypertensive patients? Could reduced BP persist after aerobic training?

What mechanisms (autonomic and hemodynamic) could be responsible for $\mathrm{PEH}$ in these resistant hypertensive patients after short-term and long-term aerobic exercise at different intensities?

\section{Methods/design}

This is a randomized controlled clinical trial with single-blind data analysis. The Standard Protocol Items: Recommendations for Interventional Trials (SPIRIT) flow chart and enrollment schedule, interventions and assessments for the trial are given in Fig. 1 and the SPIRIT Checklist in Additional file 1. Figure 2 presents 


\begin{tabular}{|c|c|c|c|c|c|}
\hline & \multicolumn{5}{|c|}{ STUDY PERIOD } \\
\hline & Enrolment & $\begin{array}{c}\text { Short-Time } \\
\text { Interventions }\end{array}$ & Allocation & Post-Allocation & Close-out \\
\hline TIMEPOINT & Screening & Acute Phase & Randomization & Aerobic Training & Revaluation \\
\hline \multicolumn{6}{|l|}{ ENROLMENT: } \\
\hline Eligibility screen & $\mathrm{X}$ & & & & \\
\hline Informed consent & $\mathrm{X}$ & & & & \\
\hline Allocation & & & $x$ & & \\
\hline \multicolumn{6}{|l|}{ INTERVENTIONS: } \\
\hline \multicolumn{6}{|l|}{$\begin{array}{r}\text { Short-time } \\
\text { Interventions }\end{array}$} \\
\hline \multicolumn{6}{|l|}{ Aerobic Training } \\
\hline \multicolumn{6}{|l|}{ ASSESSMENTS: } \\
\hline $\begin{array}{r}\text { Blood pressure } \\
\text { Monitoring }\end{array}$ & & $\mathrm{X}$ & & & $x$ \\
\hline $\begin{array}{r}\text { Autonomic } \\
\text { Variables }\end{array}$ & & $\mathrm{x}$ & & & $\mathrm{x}$ \\
\hline $\begin{array}{r}\text { Hemodynamics } \\
\text { Variables }\end{array}$ & & $\mathrm{X}$ & & & $x$ \\
\hline
\end{tabular}

Fig. 1 Standard Protocol Items: Recommendations for Interventional Trials (SPIRIT) schedule of enrollment, interventions and assessments

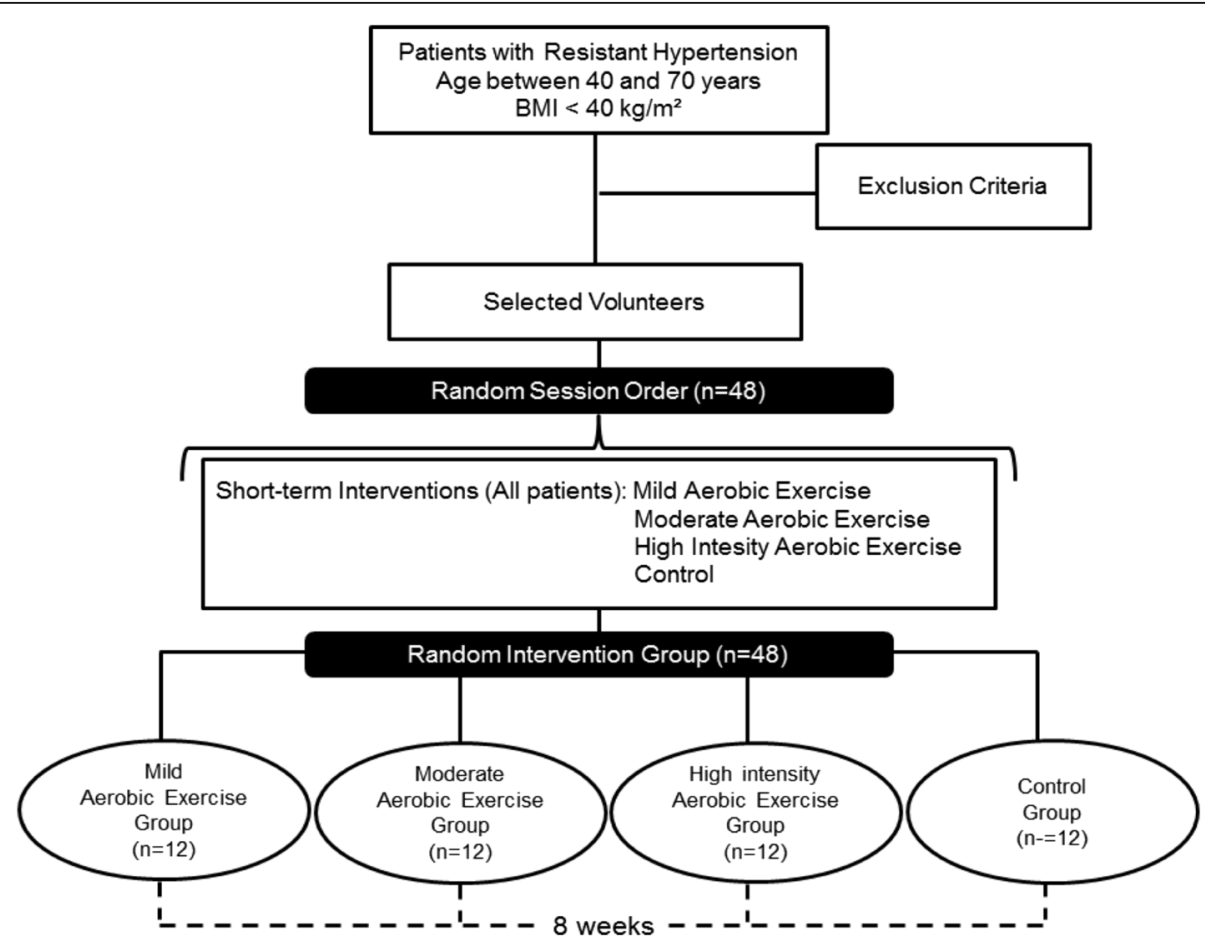

Fig. 2 Flow chart of selection and interventions. BMl: Body Mass Index. kg: kilogram. m: meter 
the experimental research design stages. In addition to ongoing medical monitoring, all individuals will be assessed by anamnesis, anthropometric measurements, biochemical tests, echocardiogram, cardiopulmonary exercise test, information about lifestyle (including dietary habits), and habits/ history of physical activity before each short-term intervention and after the follow-up period.

\section{Eligible participant and exclusion criteria}

Patients with resistant hypertension, who are aged between 40 and 70 years, will be recruited from the Lauro Wanderley University Hospital at the Federal University of Paraiba, Brazil, being men or women (women must be postmenopausal, nonmenstruating for at least 1 year and not using hormone replacement therapy), with Body Mass Index $<40 \mathrm{~kg} / \mathrm{m}^{2}$ and able to do physical exercise. Patients with resistant hypertension when BP levels are $\geq 140 / 90 \mathrm{mmHg}$ for SBP/DBP, respectively, using three or more antihypertensive agents in appropriate doses and combinations, or with controlled BP using four or more antihypertensive agents, will be considered [3] in addition to considering ambulatory BP monitoring (ABPM) records. Controlled BP will be considered for SBP and DBP: at $24 \mathrm{~h}<130 \mathrm{mmHg}$ and $<80 \mathrm{mmHg}$; awake $<135 \mathrm{mmHg}$ and $<85 \mathrm{mmHg}$; and sleeping $<120 \mathrm{mmHg}$ and $<70 \mathrm{mmHg}$ [40].

After clinical assessment and verifying medical records and biochemical data, patients can be excluded for having a history of ischemic stroke, coronary heart disease, chronic obstructive or restrictive pulmonary disease, peripheral arterial disease, hypo/hypernatremia, hyper/ hypothyroidism, chronic atrial fibrillation or a change in drug therapy for an experimental protocol. In the followup phase, patients who do not participate in $90 \%$ of the exercise training sessions, miss three consecutive training sessions or present any osteoarticular disease that prevents them from continuing the physical training program will be considered as sample loss.

\section{Random allocation sequence}

Randomization will be done using a sealed opaque envelope. All the patients will be submitted to perform four short-term interventions (within design): mild aerobic exercise, moderate aerobic exercise and high-intensity aerobic exercise and a control session, in random order and on separate days. After the short-term sessions, all the patients will be randomly allocated into four groups and followed up for 8 weeks (between design): mild aerobic exercise group, moderate aerobic exercise group, highintensity aerobic exercise group and the control group.

\section{Acute exercise interventions}

Considering the recommendations of the American College of Sports Medicine [41] and adjusting tolerance estimated by untrained resistant hypertensive patients, each aerobic exercise session will be 40 min long (warmup: $5 \mathrm{~min}$; intervention: $30 \mathrm{~min}$; and cool-down: $5 \mathrm{~min}$ ). The control session also will last $40 \mathrm{~min}$, but with rest in a seated position.

The cardiopulmonary exercise test will be used to determine the maximal aerobic capacity at peak exercise ( $\mathrm{VO}_{2}$ peak), anaerobic threshold and the respiratory compensation point. The heart rate corresponding to the anaerobic threshold and the respiratory compensation point will be used for the prescription of the mild-, moderate- and high-intensity protocols:

- Mild aerobic exercise: continuous 30-min intervention $10 \%$ below the anaerobic threshold to the anaerobic threshold point

- Moderate aerobic exercise: continuous 30-min intervention at the anaerobic threshold point to the respiratory compensation point

- High-intensity aerobic exercise: interval of 30-min intervention: 10 stimuli of $1 \mathrm{~min}$ above the respiratory compensation point with 2 min interval of passive rest after each stimulus

- Control: 40 min of rest in a seated position

\section{Aerobic exercise training}

After short-term interventions, the patients will be randomly allocated into four groups for 8 weeks, training three times per week. It will be recommended to the patients to continue with their same daily activities and food. The chronic interventions will be in the same format as the acute interventions:

- Mild aerobic exercise group: 24 sessions of continuous 30-min intervention 10\% below the anaerobic threshold to the anaerobic threshold point

- Moderate aerobic exercise group: 24 sessions of continuous 30-min intervention at the anaerobic threshold point to the respiratory compensation point

- High-intensity aerobic exercise group: 24 sessions of 30-min interval intervention: 10 stimuli of $1 \mathrm{~min}$ above the respiratory compensation point with 2-min interval of passive rest after each stimulus

- Control group: without aerobic exercise training. Patients will be instructed to not initiate any supervised physical exercise program until the end of the reevaluations

All patients will be frequently informed about the research progress and its partial results throughout the follow-up period. In addition, the researchers will maintain constant contact with the physicians responsible for each patient. The physicians and patients will receive a final report with the results at the end of study. 


\section{Measurements}

Individuals will receive the following instructions $24 \mathrm{~h}$ prior to measuring their biological signals: maintain their normal drug-use routine and sleep and meal hours; do not drink alcohol, tea, coffee, soda, or any food/drink containing caffeine. In addition, on the experiment day they will be asked to ingest a light meal $2 \mathrm{~h}$ before initiating the protocol. Patients will be asked to record their activities $24 \mathrm{~h}$ following the experiment, such as working hours, sleep schedule, meals, use of medication and any complications that they consider important (e.g., stressful situations). The same instructions will be given in the revaluation after the follow-up period.

In each short-term experimental session and follow-up phase, the biological BP signal, electrocardiogram (ECG) and blood flow will be continuously measured using $500-\mathrm{Hz}$ frequency per channel in WINDAQ software (DATAQ Instruments DI-720 Acquisition, Akron, OH, USA). BP will be recorded by ABPM (Dynamapa Car$\operatorname{dios}^{\oplus}$, São Paulo, Brazil) measured in the nondominant arm by a Dixtal $^{\bullet}$ oscillometric semiautomatic monitor (Dixtal ${ }^{\oplus}$, DX 2020, Manaus, Brazil) and by Finometer oscillometric equipment (Ohmeda 2300 Monitoring Systems, Englewood, CO, USA). BP values will be obtained immediately before exercise, 30 and $60 \mathrm{~min}$ after each intervention (ABPM, Dixtal ${ }^{\circ}$ and Finometer methods), and $24 \mathrm{~h}$ (ABPM) after the end of the intervention. ECG will be evaluated in the DII derivation (right and left arm). Forearm blood flow will be collected by venous occlusion plethysmography [42] apud [43] (Hokanson ${ }^{\circledast}$ /EC6 plethysmograph, Bellevue, WA, USA). During blood flow signal collection, $\mathrm{BP}$ values will be registered by Dixtal $^{\oplus}$ oscillometric semiautomatic monitor (Dixtal ${ }^{\oplus}$, DX 2020, Manaus, Brazil). All the measurement methods will be repeated in an experimental session without any intervention after the follow-up period in the same sequence and procedure.

\section{Outcomes \\ Primary outcome \\ Blood pressure}

For the BP measurement in the office, analysis will consider the difference between post-intervention and preintervention values. For ambulatory analysis, BP will be considered as sleep and awake periods, and the difference between 24-h post-intervention and pre-intervention values. In the follow-up analysis, baseline BP values (considering control session values without intervention) and post-training BP values will be evaluated.

\section{Secondary outcomes}

\section{Cardiac autonomic modulation}

- Linear analysis - time domain (heart rate variability) and frequency domain (absolute and normalized spectral component of low- and high-band frequencies to evaluate sympathetic and parasympathetic modulation, respectively, and autonomic balance) [44]

- Nonlinear analysis - symbolic analysis using four symbolic families (0 V\%, 1 V\%, 2LV\% and 2ULV\%) to evaluate sympathetic and parasympathetic modulation and Shannon entropy [45-47]

\section{Vasomotor autonomic modulation}

- Linear analysis - time domain (BP variability) and frequency domain: low absolute component frequency (sympathetic vasomotor index) [48]

\section{Spontaneous baroreflex sensitivity}

- Linear analysis - frequency domain method: alpha index by cross-analysis between SBP spectral power and RR interval spectral power (spontaneous baroreflex control of heart rate) $[49,50]$

\section{Forearm blood flow and peripheral vascular resistance}

- Evaluation of blood flow via assessment of the vascular tissue volume change in the forearm. The rate of the volume change is proportional to the rate of arterial inflow [43]. Forearm vascular resistance will be calculated as the ratio of mean BP and forearm blood flow

\section{Statistical analysis}

Power and sample size

Sample size was calculated using ABPM as the main outcome. Considering the high variance in the results with resistant hypertensive patients $[29,30]$ and the meta-analysis results of Fagard [28] with hypertensive patients, BP reduction after endurance training of $7 \mathrm{mmHg}$ from SBP and $5 \mathrm{mmHg}$ from DBP was used in the calculation. In order, to provide $80 \%$ power to detect a difference of $3 \mathrm{mmHg}$ between the four distinct conditions (exercise intensity and control), a total of 32 patients are indicated to give sufficient power for the study ( $n=8$ for each group). Considering the possible sample loss, 12 patients will be included in each group.

\section{Analysis plan}

Intragroup and intergroup differences between dependent variables (BP, autonomic modulation, baroreflex sensitivity, blood flow and vascular resistance) considering pre and post interventions (short-term), baseline and post intervention (dependent factor), and exercise intensities or control (independent factor) will be analyzed by two-way analysis of variance (ANOVA) for repeated measures with the Bonferroni post hoc test. Multiple linear regression 
will be used for analyzing confounding factors (dietary habits and unsupervised physical exercise practice in the follow-up period). Pearson's correlation test will be used for analyzing the relation between short-term and long-term results. Intention-to-treat will be considered for the patients with an incomplete follow-up period. A $p$ value $<0.05$ will be considered significant for all evaluations.

\section{Discussion}

The prevalence of resistant hypertension is about $10 \%$ among hypertensive patients. This number is very representative considering the overall prevalence of hypertension and consequent harm to cardiovascular health often associated with morbidity and mortality. Changes in lifestyle are continually recommended, especially in diet adjustment and regular physical exercise.

The guidelines on evaluating BP levels and resistant hypertension pay particular attention to the possibility of misdiagnosis, difficulty of adherence to a newly started treatment, adequacy of combining antihypertensive classes, adequacy of each drug dosage, as well as cases of white coat hypertension. Therefore, resistant hypertension can be real or only apparently spurious [1]. In the present study, the inclusion of each volunteer will consider medical care, medication time without changing for at least 1 year, and the use of ABPM for an appropriate confirmation of resistant hypertension.

There are only a few studies that have investigated physical exercise as an alternative therapy for resistant hypertension treatment, and they have presented promising results [29, 30, 32, 33]. However, these studies did not perform randomization, allocation blindness, appropriate pairing, or detailed description of methods (mainly statistical analysis). Also, the results are also among the main criticisms of the experts [51]. Therefore, the employed study design could hinder correctly interpreting the data, and consequently limit the scientific evidence on clinical utilization of exercise as a tool for hypertensives.

Considering the acute and chronic potential effects of exercise on $\mathrm{BP}$, the lack of responsiveness to antihypertensive drugs can adjust the mechanisms involved in $\mathrm{BP}$ control. It is possible that there is also an unexpected response to exercise, since an adverse response to exercise is not uncommon. A considerable percentage of hypertensive or nonhypertensive patients already had an adverse response in previous studies [52-54]. Thus, resistant hypertensive patients can also have difficulty attaining reduced $\mathrm{BP}$.

Finally, any analysis of BP-level modifications should look for explanations for such adjustments. Previous studies with this population analyzed peripheral [33] or central [29] variables to try to explain the reduced BP. This study aims to deepen these analyzes by simultaneously collecting signals that will be assessed at baseline and post intervention, and to evaluate central and peripheral modulatory variables through cardiovascular autonomic evaluation and vasodilatory response. The acute and chronic benefits of different exercise intensities to be described in this study could provide a new treatment strategy for resistant hypertension which could be included in clinical practice.

\section{Trial status}

The trial is still recruiting patients.

\section{Additional file}

Additional file 1: SPIRIT Fillable Checklist: recommended items to address in clinical trial protocol and related documents. (DOC $120 \mathrm{~kb}$ )

Abbreviations

ANOVA: Analysis of variance; BMI: Body Mass Index; VO 2 peak: Peak oxygen uptake

\section{Acknowledgements}

Not applicable.

Funding

Not applicable

Availability of data and materials

Not applicable.

Authors' contributions

LSN, ACS and MSBS conceived and designed the study. LSN and MSBS are responsible for managing the study. LSN and LGOS are responsible for recruiting patients, data acquisition, physical training and evaluating outcomes. LSN, ACS, AEMA and MSBS are responsible for data interpretation. LSN and JMSL calculated the power and sample size, and developed the statistical analysis plan for outcomes. LSN, ACS, JMSL, AEMA and MSBS were responsible for the critical review of the manuscript. MSBS and JMSL completed the translation of the final manuscript. All of the authors reviewed and approved the final manuscript.

\section{Authors' information}

LSN is a PhD student at the Federal University of Paraiba and professor of the Federal Institute of Pernambuco. ACS and MSBS are university professors and researchers at the Federal University of Paraiba. AEMA is a cardiologist physician and researcher from the Lauro Wanderley University Hospital at the Federal University of Paraiba, and JMSL is a professor at the Federal University of Tocantins. LGOS is an undergraduate student at the Federal University of Paraiba.

\section{Competing interests}

The authors declare that they have no competing interests.

\section{Consent for publication}

Not applicable.

\section{Ethics approval and consent to participate}

The project and the Informed Consent Form were approved by the Ethics Committee of the Health Science Center at the Federal University of Paraiba (protocol number 0602/14). All participants will be asked to sign the Informed Consent Form prior to participating in the study.

\section{Publisher's Note}

Springer Nature remains neutral with regard to jurisdictional claims in published maps and institutional affiliations. 


\section{Author details}

'Laboratório de Estudos do Treinamento Físico Aplicado a Saúde, Departamento de Educação Física, Universidade Federal da Paraíba, Castelo Branco I, CEP 58051-900 João Pessoa, Paraíba, Brasil. 2Programa Associado de Pós-Graduação em Educação Física UPE/UFPB, João Pessoa, Paraíba, Brasil. ${ }^{3}$ Universidade Federal do Tocantins, Campus Universitário de Tocantinópolis, Centro, CEP 77900-000 Tocantinópolis, Tocantins, Brasil.

\section{Received: 6 October 2016 Accepted: 15 May 2017}

Published online: 02 June 2017

\section{References}

1. European Society of Hypertension, European Society of Cardiology. 2013 ESH/ESC practice guidelines for the management of arterial hypertension. Blood Press. 2014:23(1):3-16.

2. Calhoun DA, Jones D, Textor S, Goff DC, Murphy TP, Toto RD, et al. Resistant hypertension: diagnosis, evaluation, and treatment. A scientific statement from the American Heart Association Professional Education Committee of the Council for High Blood Pressure Research. Hypertension. 2008;51(6):1403-19.

3. Chobanian AV, Bakris GL, Black HR, Cushman WC, Green LA, Izzo Jr JL, et al. The Seventh Report of the Joint National Committee on Prevention, Detection, Evaluation, and Treatment of High Blood Pressure: the JNC 7 report. JAMA. 2003;289(19):2560-72

4. Kenney MJ, Seals DR. Postexercise hypotension. Key features, mechanisms, and clinical significance. Hypertension. 1993;22(5):653-64.

5. Hara K, Floras JS. Influence of naloxone on muscle sympathetic nerve activity, systemic and calf haemodynamics and ambulatory blood pressure after exercise in mild essential hypertension. J Hypertens. 1995;13(4):447-61.

6. Halliwill JR. Mechanisms and clinical implications of post-exercise hypotension in humans. Exerc Sport Sci Rev. 2001;29(2):65-70.

7. Rueckert PA, Slane PR, Lillis DL, Hanson P. Hemodynamic patterns and duration of post-dynamic exercise hypotension in hypertensive humans. Med Sci Sports Exerc. 1996;28(1):24-32.

8. Lockwood JM, Wilkins BW, Halliwill JR. H1 receptor-mediated vasodilatation contributes to postexercise hypotension. J Physiol. 2005;563(Pt 2):633-42.

9. Higashi Y, Sasaki S, Sasaki N, Nakagawa K, Ueda T, Yoshimizu A, et al. Daily aerobic exercise improves reactive hyperemia in patients with essential hypertension. Hypertension. 1999;33(1 Pt 2):591-7.

10. Pober DM, Braun B, Freedson PS. Effects of a single bout of exercise on resting heart rate variability. Med Sci Sports Exerc. 2004;36(7):1140-8.

11. Halliwill JR, Buck TM, Lacewell AN, Romero SA. Postexercise hypotension and sustained postexercise vasodilatation: what happens after we exercise? Exp Physiol. 2013;98(1):7-18.

12. Quinn TJ. Twenty-four hour, ambulatory blood pressure responses following acute exercise: impact of exercise intensity. J Hum Hypertens. 2000;14(9):547-53.

13. Wallace JP, Bogle PG, King BA, Krasnoff JB, Jastremski CA. A comparison of 24-h average blood pressures and blood pressure load following exercise. Am J Hypertens. 1997:10(7 Pt 1):728-34.

14. Park S, Rink LD, Wallace JP. Accumulation of physical activity leads to a greater blood pressure reduction than a single continuous session, in prehypertension. J Hypertens. 2006;24(9):1761-70.

15. Taylor-Tolbert NS, Dengel DR, Brown MD, McCole SD, Pratley RE, Ferrell RE, et al. Ambulatory blood pressure after acute exercise in older men with essential hypertension. Am J Hypertens. 2000;13(1 Pt 1):44-51.

16. Pescatello LS, Turner D, Rodriguez N, Blanchard BE, Tsongalis GJ, Maresh $\mathrm{CM}$, et al. Dietary calcium intake and renin angiotensin system polymorphisms alter the blood pressure response to aerobic exercise: a randomized control design. Nutr Metab. 2007;4:1.

17. Pescatello LS, Fargo AE, Leach Jr CN, Scherzer HH. Short-term effect of dynamic exercise on arterial blood pressure. Circulation. 1991;83(5):1557-61.

18. Pescatello LS, Miller B, Danias PG, Werner M, Hess M, Baker C, et al. Dynamic exercise normalizes resting blood pressure in mildly hypertensive premenopausal women. Am Heart J. 1999;138(5 Pt 1):916-21.

19. Cleroux J, Kouame N, Nadeau A, Coulombe D, Lacourciere Y. Aftereffects of exercise on regional and systemic hemodynamics in hypertension. Hypertension. 1992;19(2):183-91.

20. Moraes MR, Bacurau RF, Ramalho JD, Reis FC, Casarini DE, Chagas JR, et al. Increase in kinins on post-exercise hypotension in normotensive and hypertensive volunteers. Biol Chem. 2007;388(5):533-40.

21. Mota MR, Pardono E, Lima LC, Arsa G, Bottaro M, Campbell CS, et al. Effects of treadmill running and resistance exercises on lowering blood pressure during the daily work of hypertensive subjects. J Strength Cond Res. 2009:23(8):2331-8.

22. Cardoso Jr CG, Gomides RS, Queiroz AC, Pinto LG, Silveira Lobo F, Tinucci T, et al. Acute and chronic effects of aerobic and resistance exercise on ambulatory blood pressure. Clinics. 2010;65(3):317-25.

23. Blumenthal JA, Sherwood A, Gullette EC, Babyak M, Waugh R, Georgiades A, et al. Exercise and weight loss reduce blood pressure in men and women with mild hypertension: effects on cardiovascular, metabolic, and hemodynamic functioning. Arch Intern Med. 2000;160(13):1947-58.

24. Miller 3rd ER, Erlinger TP, Young DR, Jehn M, Charleston J, Rhodes D, et al Results of the Diet, Exercise, and Weight Loss Intervention Trial (DEW-IT). Hypertension. 2002;40(5):612-8.

25. Moreira WD, Fuchs FD, Ribeiro JP, Appel $\amalg$. The effects of two aerobic training intensities on ambulatory blood pressure in hypertensive patients: results of a randomized trial. J Clin Epidemiol. 1999:52(7):637-42.

26. Pinto A, Di Raimondo D, Tuttolomondo A, Fernandez P, Arnao V, Licata G. Twenty-four hour ambulatory blood pressure monitoring to evaluate effects on blood pressure of physical activity in hypertensive patients. Clin J Sport Med. 2006;16(3):238-43.

27. Zanettini R, Bettega D, Agostoni O, Ballestra B, del Rosso G, di Michele R, et al. Exercise training in mild hypertension: effects on blood pressure, left ventricular mass and coagulation factor VII and fibrinogen. Cardiology. 1997;88(5):468-73.

28. Fagard $\mathrm{RH}$. Exercise is good for your blood pressure: effects of endurance training and resistance training. Clin Exp Pharmacol Physiol. 2006;33(9):853-6.

29. Dimeo F, Pagonas N, Seibert F, Arndt R, Zidek W, Westhoff TH. Aerobic exercise reduces blood pressure in resistant hypertension. Hypertension. 2012;60(3):653-8.

30. Guimarães GV, de Barros Cruz LG, Fernandes-Silva MM, Dorea EL, Bocchi EA. Heated water-based exercise training reduces 24-hour ambulatory blood pressure levels in resistant hypertensive patients: a randomized controlled trial (HEx trial). Int J Cardiol. 2014;172(2):434-41.

31. Guimarães GV, Cruz LG, Tavares AC, Dorea EL, Fernandes-Silva MM, Bocchi EA. Effects of short-term heated water-based exercise training on systemic blood pressure in patients with resistant hypertension: a pilot study. Blood Press Monit. 2013;18(6):342-5.

32. Cruz LG, Bocchi EA, Grassi G, Guimaraes GV. Neurohumoral and endothelial responses to heated water-based exercise in resistant hypertensive Patients. Circ J. 2017:81(3):339-45.

33. Santos LP, Moraes RS, Vieira PJ, Ash GI, Waclawovsky G, Pescatello LS, et al. Effects of aerobic exercise intensity on ambulatory blood pressure and vascular responses in resistant hypertension: a crossover trial. J Hypertens. 2016;34(7):1317-24

34. Eicher JD, Maresh CM, Tsongalis GJ, Thompson PD, Pescatello LS. The additive blood pressure lowering effects of exercise intensity on postexercise hypotension. Am Heart J. 2010;160(3):513-20.

35. Rogers MW, Probst MM, Gruber JJ, Berger R, Boone Jr JB. Differential effects of exercise training intensity on blood pressure and cardiovascular responses to stress in borderline hypertensive humans. J Hypertens. 1996; 14(11):1369-75.

36. Pescatello LS, Guidry MA, Blanchard BE, Kerr A, Taylor AL, Johnson AN, et al. Exercise intensity alters postexercise hypotension. J Hypertens. 2004; 22(10):1881-8.

37. Hagberg JM, Montain SJ, Martin 3rd WH, Ehsani AA. Effect of exercise training in 60- to 69-year-old persons with essential hypertension. Am J Cardiol. 1989;64(5):348-53.

38. Ciolac EG, Guimaraes GV, VM DA, Bortolotto LA, Doria EL, Bocchi EA. Acute effects of continuous and interval aerobic exercise on 24-h ambulatory blood pressure in long-term treated hypertensive patients. Int J Cardiol. 2009:133(3):381-7.

39. Marceau M, Kouame N, Lacourciere $Y$, Cleroux J. Effects of different training intensities on 24-hour blood pressure in hypertensive subjects. Circulation. 1993;88(6):2803-11.

40. O'Brien E, Parati G, Stergiou G, Asmar R, Beilin L, Bilo G, et al. European Society of Hypertension position paper on ambulatory blood pressure monitoring. J Hypertens. 2013;31(9):1731-68.

41. American College of Sports Medicine. ACSM's guidelines for exercise testing and prescription. 9th ed. 2014

42. Hokanson DE, Sumner DS, Strandness Jr DE. An electrically calibrated plethysmograph for direct measurement of limb blood flow. IEEE Trans Biomed Eng. 1975;22(1):25-9. 
43. Lekakis J, Abraham P, Balbarini A, Blann A, Boulanger CM, Cockcroft J, et al Methods for evaluating endothelial function: a position statement from the European Society of Cardiology Working Group on Peripheral Circulation. Eur J Cardiovasc Prev Rehabil. 2011;18(6):775-89.

44. Task Force of the European Society of Cardiology and the North American Society of Pacing and Electrophysiology. Heart rate variability. Standards of measurement, physiological interpretation, and clinical use. Eur Heart J. 1996;17(3):354-81.

45. Guzzetti S, Borroni E, Garbelli PE, Ceriani E, Della Bella P, Montano N, et al. Symbolic dynamics of heart rate variability: a probe to investigate cardiac autonomic modulation. Circulation. 2005;112(4):465-70.

46. Porta A, Guzzetti S, Montano N, Furlan R, Pagani M, Malliani A, et al. Entropy, entropy rate, and pattern classification as tools to typify complexity in short heart period variability series. IEEE Trans Biomed Eng. 2001;48(11):1282-91.

47. Porta A, Tobaldini E, Guzzetti S, Furlan R, Montano N, Gnecchi-Ruscone T. Assessment of cardiac autonomic modulation during graded head-up tilt by symbolic analysis of heart rate variability. Am J Physiol Heart Circ Physiol. 2007;293(1):H702-H8.

48. Mancia G, Parati G, Pomidossi G, Casadei R, Di Rienzo M, Zanchetti A. Arterial baroreflexes and blood pressure and heart rate variabilities in humans. Hypertension. 1986;8(2):147-53.

49. Robbe HWJ, Mulder LM, Ruddel H, Veldman JBP, Langewitz WA, Mulder G. Assessment of baroreflex sensitivity by means of spectral analysis. Hypertension. 1987:10:538-43.

50. Pagani M, Somers V, Furlan R, Dell'Orto S, Conway J, Baselli G, et al. Changes in autonomic regulation induced by physical training in mild hypertension. Hypertension. 1988;12(6):600-10.

51. Ash Gl, Macdonald HV, Pescatello LS. Antihypertensive effects of exercise among those with resistant hypertension. Hypertension. 2013;61(1):e1.

52. Leifer ES, Mikus CR, Karavirta L, Resnick BD, Kraus WE, Hakkinen K, et al. Adverse cardiovascular response to aerobic exercise training: is this a concern? Med Sci Sports Exerc. 2016;48(1):20-5.

53. Bouchard C, Blair SN, Church TS, Earnest CP, Hagberg JM, Hakkinen K, et al. Adverse metabolic response to regular exercise: is it a rare or common occurrence? PLoS ONE. 2012;7(5):e37887.

54. Hagberg JM, Park JJ, Brown MD. The role of exercise training in the treatment of hypertension: an update. Sports Med. 2000;30(3):193-206.

\section{Submit your next manuscript to BioMed Central and we will help you at every step:}

- We accept pre-submission inquiries

- Our selector tool helps you to find the most relevant journal

- We provide round the clock customer support

- Convenient online submission

- Thorough peer review

- Inclusion in PubMed and all major indexing services

- Maximum visibility for your research

Submit your manuscript at www.biomedcentral.com/submit 